\title{
Effect of Different Training Methods on Forearm and Reception Pass Techniques in Males Volleyball Players*
}

\author{
M. Emin Kafkas, Armağan Şahin Kafkas \\ Inonu University, Malatya, Turkey
}

\author{
Ivan Růžička \\ Univerzita Hradec Králov, Olomoucký, Czech Republic
}

\begin{abstract}
The purpose of this research was to evaluate the forearm and reception-pass score changes after both visual and verbal pass equipment training in male volleyball players. The major hypothesis of this research was that visually enhanced feedback would be more effective than verbal feedback. Forty-eight volleyball male players at the age of 21.3 \pm 4.70 , height $187.50 \pm 9.70$, body weight $76.20 \pm 5.10$ and sport experience 5.0 volunteered to take part in the investigation after having explained to them the purposes of the study. The participants were randomly separated into two groups: Visual-Feedback Group (VFG, $n=8$ ) and Verbal-Feedback Group (VRFG, $n=8$ ). The groups were measure forearm and reception pass scores before training season. During 12 weeks training season, VFG and VRFG participants had trained three times a week (Monday, Wednesday, and Friday). The measurements of participants pass performance evaluated that was developed by researcher with a scale. The scale measured pass score of participants each successful pass 10 points and each unsuccessful pass -5 points at specific target. Participants were implemented 20 passes that both forearm pass (10) for number of two zone and reception pass (10) for number of six zones in volleyball respectively. Analyses showed that significant differences between two different feedback method of groups $(p<0.05)$. Differences in mean rating of forearm and reception-pass test in VFG were significantly different between pre- and post-test $(p<0.05)$. Measurements of forearm and reception pass values were significant found in favor of post-tests values of VRFG $(p<0.05)$. Finally, differences in mean rating of forearm and reception-pass test were found out significant in favor of VFG between VFG and VRFG. This study finding also showed that the specific apparatus had effect on learning of forearm and reception pass tasks. This research concluded that differences in performance of forearm and reception pass tasks might be related to the provision of visual feedback.
\end{abstract}

Keywords: feedback, forearm, reception, and volleyball

\section{Introduction}

Feedback is taken into one of the most important teaching functions (Rink, 2002). When feedback is provided in a suitable manner, motor skill acquisition enhances substantially (Schmidt \& Lee, 2005). The term "feedback" generically describes; "information a person receives about his or her performance during or after

\footnotetext{
* Acknowledgments: The authors wish to thank all the participants for their participation and commitment to the study. Also, we are very grateful for the English editing of Dr Ali Tekin. This research was supported by a fund from Inonu University Scientific Research Projects Unit (2012-105). This study was partially presented as an oral presentation at the ERPA International Congress on Education 2015/Athens.

M. Emin Kafkas, School of Physical Education and Sport, Department of Coaching Education, Inonu University.

Armağan Şahin Kafkas, School of Physical Education and Sport, Department of Coaching Education, Inonu University.

Ivan Růžička, Ph.D., Katedra tělesné výchovy a sportu, Pedagogická fakulta, Univerzita Hradec Králové.
} 
execution”. Feedbacks coming from the person's own sensory-perceptual system (intrinsic feedback) is a natural consequence of movement. Feedback coming from a source that is external to the performer (augmented feedback) supplies intrinsic feedback and adds information to that naturally available (Magill, 2001). Trainers and teachers generally ensure their athletes and pupils with increased feedback to help them correct errors, reinforce proper execution, and motivate them to persevere and improve in the face of difficulties and setbacks (Bortoli, Bertollo, Messina, Chiariotti, \& Robazza, 2010; Coker, Fischman, \& Oxendine, 2006; Smith, 2006). Coaching is highly competitive and trainers usually search ways of reaching an added advantage over the competition. Getting an advantage over an opposing team can come in a variety of ways: through developed practice, better drills, improved communication with players, and instruction in advanced techniques (Rhoads, 2012). Numerous studies have examined variations in these coaching practices. Early studies examined traditional approaches to coaching whereby verbal instruction was provided followed by verbal feedback. The research on using verbal cues as a way to direct learning overwhelmingly shows this to be an effective method of instruction (Kountouris \& Laios, 2007). The importance of visual information in the learning process is well known. Consider that, on average, people learn $1 \%$ through what they taste, $1.5 \%$ through what they touch, $3.5 \%$ through what they smell, $11 \%$ through what they hear, but $83 \%$ through what they see. Research also finds that individuals retain $10 \%$ of what they write, $20 \%$ of what they hear, $30 \%$ of what they see, $50 \%$ of what they see and hear, and $70 \%$ of what they discuss (Simatos, 2000).

The choice of pass techniques for this research was based upon its substantial to the sport of volleyball. The overhead pass techniques commonly performed to setter, and the forearm pass is the primary skill utilized to reception a serve. Rydberg (2011) stated that being successful in a match, they should side out (win a rally initiated by the opponents' serve) better than $60 \%$ of the time. The first step to siding out is the pass. If the first contact (the pass) is good, the second contact (the set) is more possibly to be effective and the third contact (the attack) is more likely to be successful in attaining a kill (an attack that cannot be returned by the opponents). Zetou, Moustakidis, Tsigilis, and Komninakidou (2007) strongly confirms these assertion, they found that statistically perfect and near perfect passes were key to teams' accomplishment in competitions analyzing the 2004 Olympic Games in Athens. That is true because, for elite players, set quality rely on pass quality, and attack quality depends on set quality (Daniel \& Hughes, 2003). The effects on skill learning of different types of increased feedback and instructional patterns have been researched extensively in laboratory settings and in the context of schools. But, more investigation is needed into the communication patterns in the real-world sporting environment. In the literature, no study examined the forearm and reception-pass score changes after both visual and verbal pass equipment training in male volleyball players. Therefore, the purpose of this research was to evaluate the forearm and reception-pass score changes after both visual and verbal pass equipment training in male volleyball players. The major hypothesis of this research (1) regular forearm and reception pass training would improve forearm and reception pass scores; (2) was that visually-enhanced feedback would be more effective than verbal feedback.

\section{Methods}

\section{Participants}

Forty-eight volleyball male players at the age of $21.3 \pm 4.70$, height $187.50 \pm 9.70$, body weight $76.20 \pm 5.10$ and sport experience 5.0 volunteered to take part in the investigation after having explained to them the purposes of the study. Informed consent was obtained from them prior to their participation in the study. 
Participants were college volleyball players. A sample size of 48 was deemed adequate for this study using a sample size calculator for a crossover design. According to the sample size calculator, a minimum of 19 participants was necessary to detect significance at a one-sided 0.05 significance level with power set at $90 \%$ (G-Power 3.1.7). Players faced the risk of injury and fatigue; these risks were addressed by having participants warm up before each training session and cool down and stretch after each session. All participants have been sufficiently informed about the importance of the study and of the risks involved. All procedures implemented in the study comply with the Helsinki declaration.

\section{Training Procedure}

The participants were randomly separated into two groups: Visual-Feedback Group (VFG, $n=8$ ) and Verbal-Feedback Group (VRFG, $n=8$ ). The groups were measure forearm and reception pass scores before training season. During 12 weeks training season, VFG and VRFG participants had trained three times a week (Monday, Wednesday, and Friday). All participants carried out 10 sets $\times 30$ repetitions forearm and reception passes. All participants were made to warm up before starting the pass training sessions. Two coaches made all test and training session and all participants were motivated verbally during the study. All participants were made to perform cooling exercises for $10 \mathrm{~min}$ of their training session period at the end of working out (see Table 1).

Table 1

Training Procedure Schedule

\begin{tabular}{|c|c|c|c|}
\hline Sessions & Practices & Set $\times$ Repetition & Duration \\
\hline Warm up & $\begin{array}{l}\text { Stretching, } \\
\text { Slowly running or jogging, } \\
\text { Slightly stretching and flexibility exercise, } \\
\text { Specific volleyball drills (throw ball, pass etc.) }\end{array}$ & None & $15 \mathrm{~min}$ \\
\hline Main course & $\begin{array}{l}\text { Forearm pass, } \\
\text { Reception pass. }\end{array}$ & $10 \times 30$ & $45 \mathrm{~min}$ \\
\hline Cool down & Stretching. & None & $10 \mathrm{~min}$ \\
\hline
\end{tabular}

\section{Measurements of Pass Performance}

The measurements of participants pass performance evaluated that was developed by researcher with a scale. The scale measured pass score of participants each successful pass 10 points. Participants were implemented 20 passes which both forearm pass (10) for two number zone and reception pass (10) for six number zones in volleyball respectively. All measurements recorded by two video cameras (Sony, Handycam, Japan). These records viewed and after test sessions were recorded. Data of participants were assessed available a scale developed by researchers (see Table 2).

Table 2

Developed Score Scale

\begin{tabular}{ll}
\hline Score & Level \\
\hline $165-200$ & Excellent \\
$130-164$ & Good \\
$95-129$ & Average \\
$60-94$ & Poor \\
$0-59$ & Very poor \\
\hline
\end{tabular}




\section{Equipment}

Target challenger. Adjustable pole height and target ring allow for multi-purpose use to accommodate any volleyball techniques. Strong net pick ops balls for easy retrieval. Target challenger has included $10 \mathrm{~kg}$ weight for stability and 2 wheels for easy portability. Adjustable to 3.65 feet, target ring measures 30". Target challenger is ideal for pass, setting, or shooting.

Bask it. The talents of pass, setting, serving and spiking have been need constant perfecting. For this reason we developed the "Bask It". The "Bask It" is an adjustable target that collects balls for more efficient use in drills. The "Bask It" multiple adjustments make it ideal for refining the skills of pass, serving, spiking and setting. The "Bask It" is the perfect motivational tool for your volleyball drills.

\section{Statistical Analysis}

Statistical analyses were implemented with the aid of a package program (SPSS, version 17.0). Data are presented as mean \pm standard deviation. Statistical analysis procedures started with "Skewness and Kurtosis" scores, visual explanations of histogram plots. Later was used "Shapiro Wilk Test" (for the number of sample is smaller than 50) in order to test whether data were homogenous. As variances show not a normal distribution, the testing times of groups were analyzed by "Mann Whitney U Test", analysis was used to test for significant differences between groups. In addition to the statistical significance levels of the pre and post- training values were determined by "Wilcoxon Rank Test". A significance level $p<0.05$ was used in all statistical analyses. The reliability of each forearm and reception pass test was assessed by intra-class correlation coefficient (ICC) as suggested by Weir (2005). The results indicated that these tests were highly repeatable: ICC of forearm passes was $(\mathrm{ICC}=0.91)$ and reception passes $(\mathrm{ICC}=0.90)$.

\section{Results}

Baseline and twelve weeks forearm pass values were showed in Figure 1. Analyses showed that significant differences between two the different feedback method of groups $(p<0.05)$. Measurements of forearm pass values were significant found in favor of post-tests values of VRFG $(p=0.001)$. As shown in Figure 1 , the post-test of forearm pass scores were remarkably greater than pre-test pass scores for VFRG.

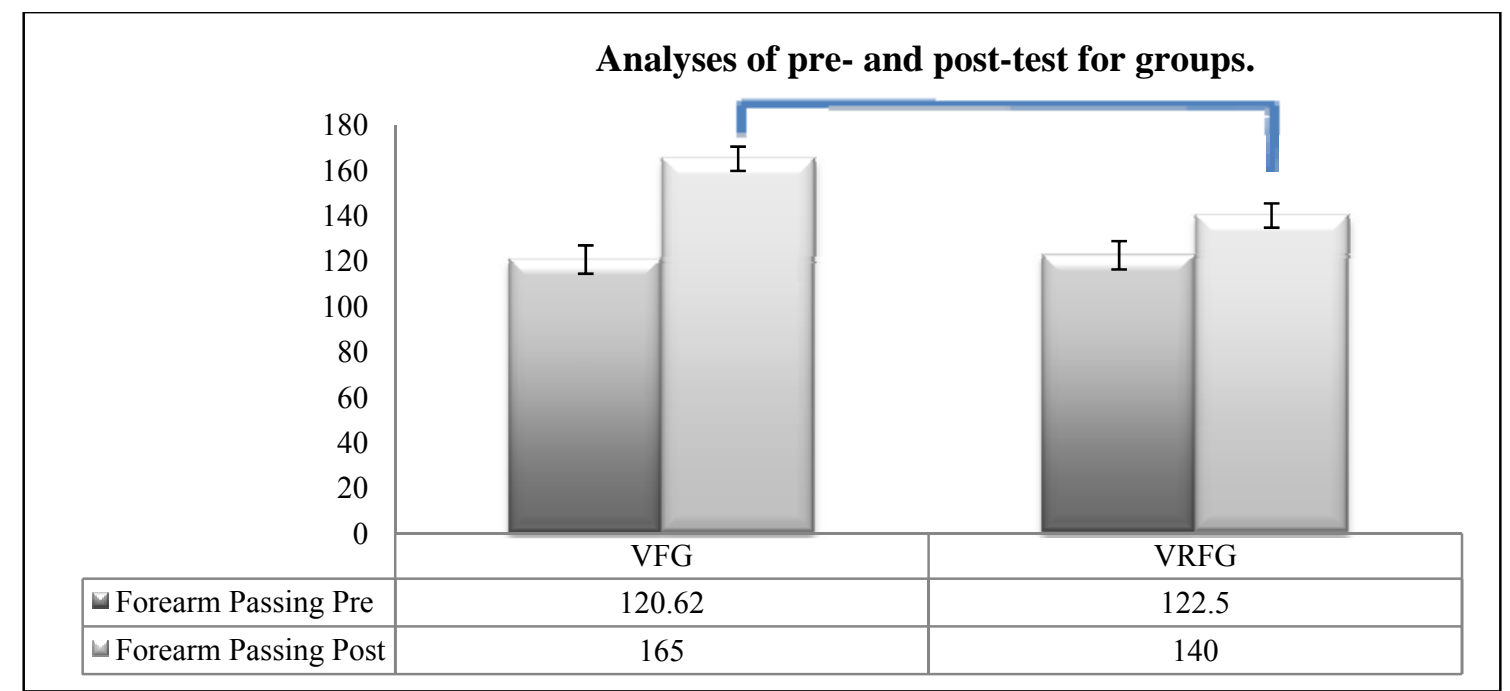

Figure 1. Analyses of pre- and post-test for forearm pass (VFG: visual feedback group, VFRG: verbal feedback group, ${ }^{\mathrm{a}}$ : significantly difference between pre- and post-test, ${ }^{\mathrm{b}}$ : significantly difference between VFG and VRFG). 
Baseline and twelve weeks reception pass values were showed in Figure 2. The Figure 2 indicated that significant differences between two the different feedback method of groups $(p<0.05)$. Measurements of reception pass values were significant found in favor of post-tests values of VRFG $(p=0.001)$. As shown in Figure 2, the post-test of reception pass scores were remarkably greater than pre-test pass scores for VFRG.

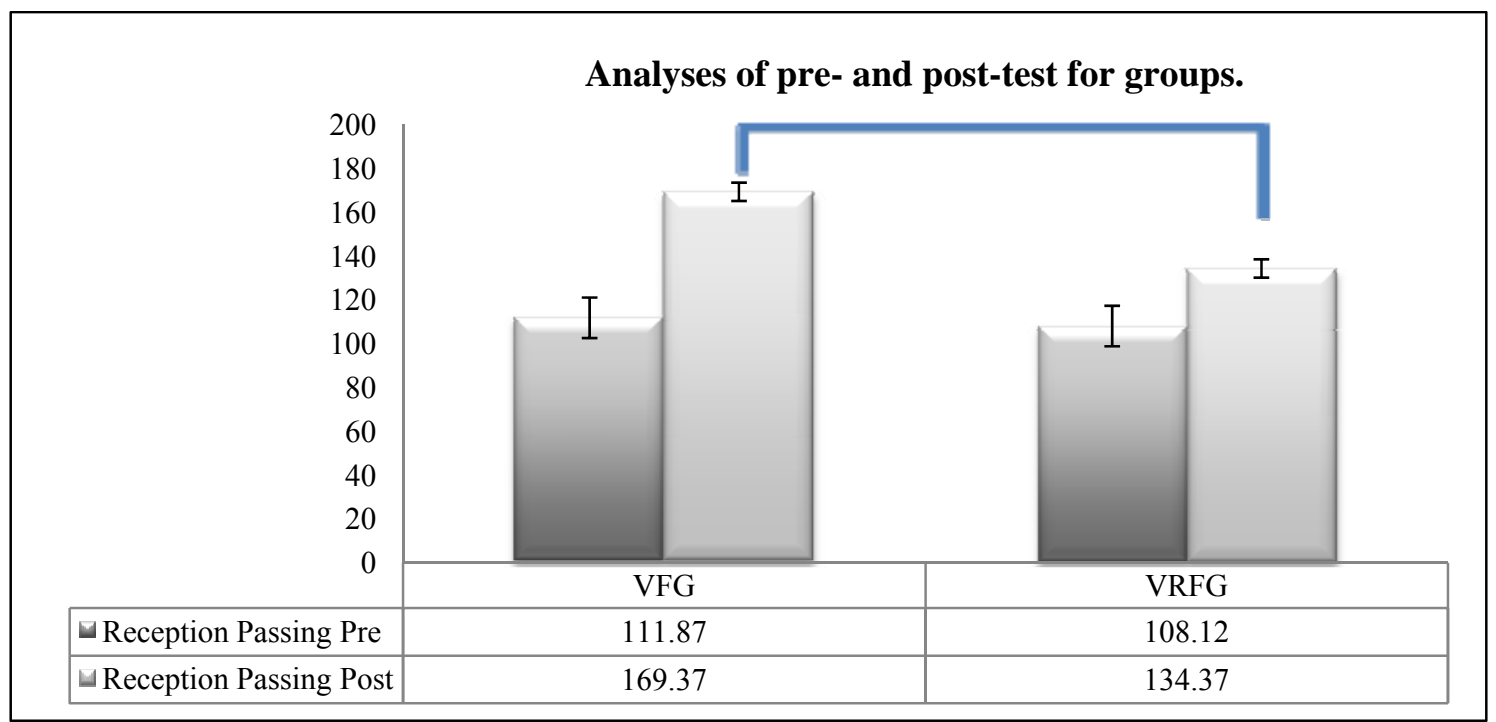

Figure 2. Analyses of pre- and post-test for reception pass (VFG: visual feedback group, VFRG: verbal feedback group, ${ }^{\text {a }}$ : significantly difference between pre- and post-test, ${ }^{\text {b}}$ : significantly difference between VFG and VRFG).

\section{Discussion and Conclusions}

The primary aim of this research was to investigate the effectiveness visual feedback in learning motor talents. It is a well-establish fact that both visual and verbal feedbacks play a very substantial role in motor learning and control (Kirazci, 2013; Coker, Fischman, \& Oxendine, 2006; Kawasima et al., 2000). In addition to the amount of feedback can influential learning a skill in several ways, because frequent feedback has been found to improve acquisition of the ability but less frequent feedback improve constraint of talent (Akpinar, Devrilmez, \& Kirazc1, 2012). Various different apparatus were used in the application of visual feedback, which is getting progressively substantial considering a scarcity of experimental evidence that backups such utilize. Along with this necessity, a number of variants that might improve the effectiveness of visual feedback guarantee further researches. Besides, few studies have researched the learner's thoughts whilst learning with visual feedback on volleyball players (Rhoads, 2012). This research was to determine statistically if visual feedback was superior to verbal feedback when training volleyball players to forearm and reception pass. Volleyball players in this research had a background of similar volleyball experience. Therefore, the effect of visual and verbal feedback on the learning of the task was accepted to be the similar both feedback groups. To evaluate differences between verbal and visual feedback, an experimental crossover design was implemented. To address study hypotheses, based on an ANOVA contrast, it was explored that volleyball players enhanced significantly from the pre- to posttest measurements. The outcomes of this study were incoherent with previous researches. Previous studies showed that both visual and verbal feedback at the same time to the volleyball players in an experimental group and have observed improvement of learning (Campenalla, Mattacola, \& Kimura, 2000; Kirazci, 2013). In a meta-analysis examining studies that compared verbal and visual feedback, 
was showing a slight advantage for the use of visual feedback (Rhodes \& Anastasia 2012). Another investigation also compared these two types of procedures and obtained a trivial advantage from using visual feedback (Rhoads, 2012). But, Carroll and Bandura (1987) suggested a more sensible reason was that visual feedback administrated to knowledge overload for the learner and ensured more information than the learner was able to process. The wider quantity of common, affirmative, reformative feedback ensured to single individuals after performance most probably mirrored the volleyball players' aims to toward the right understanding and practice of volleyball tasks. These conditions were not astonishing because this was fundamentally the point of the role played by trainers as simplifiers of motor talent ascertain and improvement (Bortoli et al., 2010; Coker, Fischman, \& Oxendine, 2006). Astonishing differences were found between visual and verbal feedback, in that the visual feedback may utilized more effective, correct, performance feedback and self-control. The most of striking finding my study is visual feedback more beneficial than verbal feedback. So, especially forearm pass very important is for volleyball teams. In the literature, the most of important two technics have addressed reception and forearm pass for volleyball matches. In the last Olympic Games revealed that if the first pass is good then second pass is more possible to be effect. Lastly, if setters throw good forearm pass, the offences are more possible to may affect. Therefore, these study findings are both important and original in terms of volleyball training. The study finding also showed that the specific apparatus had effect on learning of forearm and reception pass tasks. This research concluded that differences in performance of forearm and reception pass tasks might be related to the provision of visual feedback. Our study aided to understand the relative value of visual feedback compared to verbal feedback in teaching motor skills. We found that visual feedback more effective for volleyball players in our research. In light of the research findings, visual feedback pass teaching method would benefit the development of forearm and reception pass technique. Also, volleyball coaches would be able to improve the success rate of forearm and reception pass with different training apparatus ("bask it and target challenger"). But, after completing the research, a number of limitations as well as suggestions for future study are worth debating. Initially, the low sample size was an area of concern. A larger sample size would permit for more definitively generalizable results. Later, volleyball players in the experiment were not diverse. All volleyball players were male and all of them were white and came from low or middle class backgrounds. Future researches should examine use greater numbers of players and individuals from both genders from a variety of ethnic backgrounds and income levels.

\section{References}

Akpinar, S., Devrilmez, E., \& Kirazci, S. (2012). Coincidence-anticipation timing requirements are different in racket sports. Perceptual and Motor Skills, 115, 581-593.

Bortoli, L., Bertollo, M., Messina, G., Chiariotti, R., \& Robazza, C. (2010). Augmented feedback of experienced and less experienced volleyball coaches: A preliminary investigation. Social Behavior and Personality: An International Journal, 38(4), 453-460.

Campenalla, B., Mattacola, C. G., \& Kimura, I. F. (2000). Effect of visual feedback and verbal encouragement on concentric quadriceps and hamstrings peak torque of males and females. Isokinetics and Exercise Science, 8, 1-6.

Carroll, W. R., \& Bandura, A. (1987). Translating cognition into action: The role of visual guidance in observational learning. Journal of Motor Behavior, 19, 385-398.

Coker, C. A., Fischman, M. G., \& Oxendine, J. B. (2006). Motor skill learning for effective coaching and performance. In J. M. Williams (Ed.), Applied sport psychology: Personal growth to peak performance (5th ed., pp. 18-40). New York: McGraw-Hill Companies.

Daniel, R., \& Hughes, M. (2003). Playing patterns of elite and non-elite volleyball. International Journal of Performance Analysis in Sport, 3(1), 50-56. 
Kawasima, R., Tajima, N., Yoshida, H., Okita, K., Sasaki, T., Schormann, T. et al. (2000). The effect of verbal feedback on motor learning: A PET study. Neuro Image, 12, 698-706.

Kirazci, S. (2013). Effects of verbal and visual feedback on anticipation timing. Social Behavior \& Personality: An International Journal, 41(7).

Kountouris, P., \& Laios, Y. (2007). The effectiveness of external cues on learning spiking in volleyball. International Journal of Performance Analysis in Sport, 7, 117-125.

Magill, R. A. (2001). Augmented feedback in motor skill acquisition. In R. N. Singer, H. A. Hausenblas, \& C. M. Janelle (Eds.), Handbook of sport psychology (2nd ed., pp. 86-114). New York: John Wiley \& Sons.

Rhoads, C. M. (2012). Learning to spike in volleyball with verbal and visually-enhanced feedback (Doctorate dissertation, University of Northern Colorado).

Rhodes, M. G., \& Anastasi, J. S. (2012). The own-age bias in face recognition: A meta-analytic and theoretical review. Psychological Bulletin, 138(1), 146.

Rink, J. E. (2002). Teaching physical education for learning (4th ed.). New York: McGraw-Hill.

Rydberg, N. (2011). The effect of self-controlled practice on forearm passing, motivation, and affect in women's volleyball players (Masters of Science Degree, University of Nevada, Las Vegas).

Schmidt, R. A., \& Lee, T. D. (2005). Motor control and learning: A behavioural emphasis (4th ed.) Champaign, IL: Human Kinetics.

Simatos, A. (2000). Technology and education. Athens: Patakis Press.

Smith, R. E. (2006). Positive reinforcement, performance feedback, and performance enhancement. In J. M. Williams (Ed.), Applied sport psychology: Personal growth to peak performance (5th ed., pp. 41-57). New York: McGraw-Hill Companies.

Weir, J. P. (2005). Quantifying test-retest reliability using the intraclass correlation coefficient and the SEM. J. Strength Cond Res, 19, 231-240.

Zetou, E., Moustakidis, A., Tsigilis, N., \& Komninakidou, A. (2007). Does effectiveness of skill in complex I predict win in Men's Olympic volleyball games? Journal of Quantitative Analysis in Sports, 3(4), 1-9. 